\title{
Tomografi Seismik Menggunakan Full Waveform Inversion pada Studi Kasus Zona Kecepatan Rendah
}

\author{
Muhammad Akbar Najib . H ${ }^{(1, a)^{*}}$,Ade Indra Gurada . $C^{(1)}$ dan Reinaldi Juniarto ${ }^{(1)}$ \\ (1) Fakultas Teknologi Mineral, UPN"Veteran" Yogyakarta, DIY, Indonesia, 55283 \\ Email: ${ }^{\left(a^{*}\right)}$ akbarnajib@gmail.com
}

Diterima (25 September 2020), Direvisi (21 Juni 2021)

\begin{abstract}
This paper investigates near surface velocity imaging in the full waveform inversion (FWI). Conventional traveltime tomography may produce inaccurate result for imaging low velocity zone. FWI compute synthetic seismic shot gathers associated with initial velocity depth model by acoustic finite difference forward modeling. The velocity model is updated by iteratively back propagate waveform residual to update velocity model. This method is applied to synthetic 2-D land data which has complex structure and low velocity zone beneath the high velocity layer. We compare near-surface velocity models derived from traveltime tomography and FWI at simple model. The result is traveltime tomography produces inaccurate result for low velocity anomaly in 2-D land synthetic seismic data, than FWI. In addition, FWI can further improve the near surface velocity model which shows greater vertical and lateral resolution and reveals low velocity zone that is not present in the traveltime tomography. Near surface imaging affects the result of static correction in preprocessing stage. More accurate near surface velocity model, more satisfied the result of static correction. The pre-stack time migration (PSTM) section using statics from FWI model led to more accurate time imaging results compared to PSTM section using traveltime tomography velocity model. Nowadays, in the oil and gas industry, the exploration of hydrocarbon is located in complex structure. FWI is a high-end method and needed to produce seismic image accurately.
\end{abstract}

Keywords: FWI, low velocity zone, PSTM, tomography, travel time.

\begin{abstract}
Abstrak. Paper ini menginvestigasi model kecepatan dekat permukaan menggunakan full waveform inversion (FWI). Metode konvensional travetime tomography menghasilkan hasil yang kurang akurat pada pemodelan zona velocity rendah. FWI menghitung shot gather seismik sintetik terkait dengan model kedalaman kecepatan awal dengan forward modelling finite difference parsial. Model kecepatan diupdate secara propagasi gelombang secara iterative untuk memperbaruhi model kecepatan. Metode ini diterapkan pada data sintetik darat 2-D yang memiliki struktur kompleks dan zona kecepatan rendah di antara lapisan kecepatan ting gi. Kami membandingkan model kecepatan dekat permukaan yang berasal dari traveltime dan FWI tomografi pada model kecepatan sintetik sederhana dan kompleks. Hasilnya traveltime tomografi memberikan hasil yang tidak akurat untuk anomali kecepatan rendah pada data seismik sintetik darat 2-D, dibandingkan FWI. Selain itu, FWI dapat meningkatkan model kecepatan dekat permukaan yang menunjukkan resolusi vertikal dan lateral yang lebih baik serta menunjukkan zona kecepatan rendah yang tidak terdapat dalam traveltime tomografi. Penggambaran dekat permukaan mempengaruhi hasil koreksi statik. Penampang pre stack time migration (PSTM) menggunakan FWI model menghasilkan hasil yang lebih akurat dibanding dengan menggunakan traveltime tomografi. Dalam industri migas saat ini eksplorasi hidrokarbon berada pada struktur yang kompleks. FWI merupakan metode high-end dan dibutuhkan untuk menghasilkan citra seismik secara akurat.
\end{abstract}

Kata kunci: FWI, PSTM, tomografi, traveltime, zona kecepatan rendah . 
Muhammad Akbar Najib .H: Tomografi Seismik Menggunakan Full Waveform Inversion Pada Studi Kasus Zona Kecepatan Rendah

Jurnal Migasian, e-issn : 2615-6695 / p-issn: 2580-5258

\section{PENDAHULUAN}

Pada studi seismik, terdapat suatu teknik yang digunakan untuk menggambarkan keadaan bawah permukaan dengan melakukan tomografi. Traveltime tomografi merupakan salah satu cara konvensional untuk merekonstruksi model kecepatan bawah permukaan yang didapat dari picking traveltime. Namun, metode traveltime tomography memiliki kelemahan dalam memberikan gambaran yang lebih baik pada kondisi geologi yang kompleks, terutama pada zona hidden layer. Oleh karena itu, diperlukan pendekatan lain dalam mengatasi tantangan imaging subsurface yang dikenal dengan Full Waveform Inversion (FWI).

Metode ini memanfaatkan hasil velocity model traveltime tomografi dimana memperhitungkan shot gather seismik sintetik dengan initial model. Proses yang diterapkan yaitu forward modelling finite difference akustik. Iterasi dilakukan dengan propagasi gelombang secara iteratif hingga ketidakcocokan data cukup kecil dan diharapkan dapat meningkatkan resolusi model kecepatan serta menggambarkan zona hidden leyer.

Tujuan dari penelitian ini adalah untuk mendapatkan model kecepatan, penamapang Pre Stack Time Migration (PSTM) hasil FWI tomography yang menunjukan anomali zona kecepatan rendah. Apabila model kecepatan FWI tomografi dari model sintetik sederhana terbukti dapat menggambarkan bawah permukaan dengan lebih baik (dalam kasus ini), maka diterapkan pada model sintetik kompleks untuk menguji keabsahan metode ini.

\section{METODOLOGI}

\section{Data}

Dalam penelitian ini dilakukan pemodelan tomografi terhadap model sintetik berupa data model sintetik sederhana dan kompleks darat 2D yang memiliki offset $10.000 \mathrm{~m}$ dengan kedalaman $1.500 \mathrm{~m}$ dengan variasi kecepatan interval. Berikut merupakan model sintetik sederhana dan kompleks pada penelitian ini.

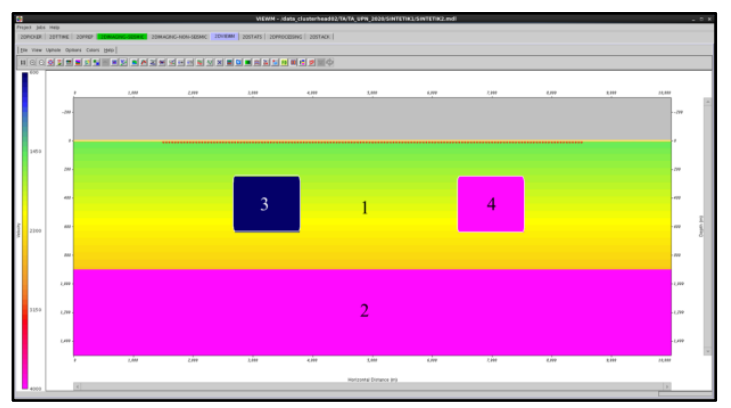

(a)

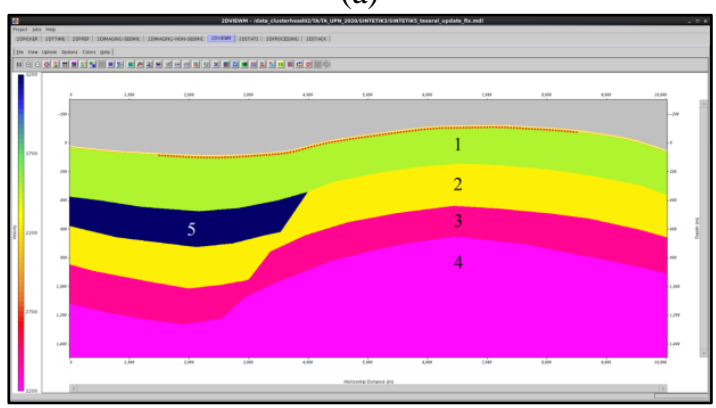

(b)

Gambar 1. Model sintetik sederhana dan model sintetik kompleks

Tabel 1. Parameter kecepatan gelombang $P$ dari tiap objek pada model sintetik sederhana

\begin{tabular}{clc}
\hline No & \multicolumn{1}{c}{ Objek } & $\mathbf{V p}(\mathbf{m} / \mathbf{s})$ \\
\hline 1 & Lapisan 1 & $1500-2500$ \\
2 & Lapisan 2 & 4000 \\
3 & $\begin{array}{l}\text { Anomali kecepatan } \\
\text { rendah }\end{array}$ & 600 \\
& $\begin{array}{l}\text { Anomali kecepatan } \\
\text { tinggi }\end{array}$ & 4000 \\
\hline
\end{tabular}


Tabel 2. Parameter kecepatan gelombang P dari tiap objek pada model sintetik kompleks

\begin{tabular}{clc}
\hline No & \multicolumn{1}{c}{ Objek } & Vp $(\mathbf{m} / \mathbf{s})$ \\
\hline 1 & Lapisan 1 & 1900 \\
2 & Lapisan 2 & 2150 \\
3 & Lapisan 3 & 3000 \\
4 & Lapisan 4 & 3200 \\
5 & Anomali zona & 1200 \\
& kecepatan rendah & \\
\hline
\end{tabular}

\section{Diagram Alir}

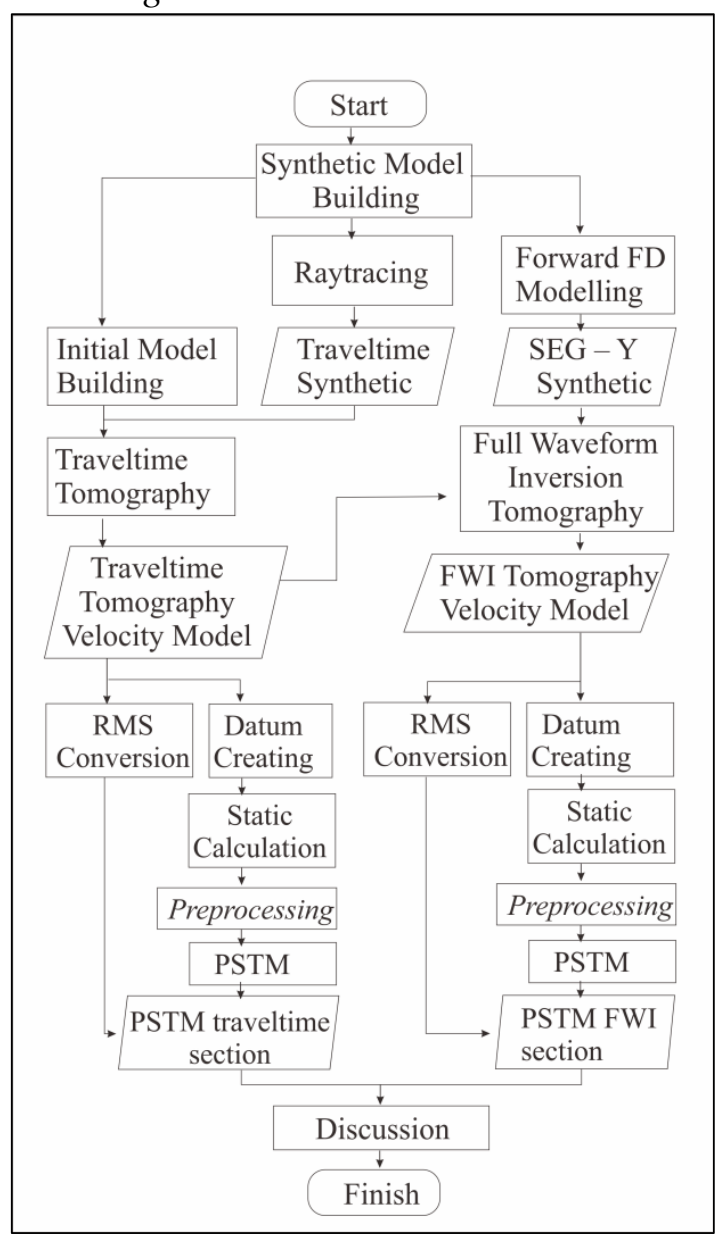

Gambar 2. Diagram alir penggambaran tomografi menggunakan travel time dan FWI tomografi

Data model awal berupa model sintetik sederhana dan model sintetik kompleks. Data seismik sintetik didapatkan dari hasil forward modelling kedua model sintetik tersebut dengan simulasi akuisisi seismik menggunakan software GeoTomo TomoPlus serta source geophone.
Pengolahan data model sintetik sederhana dilakukan hingga FWI tomografi, sedangkan untuk validasi model sintetik kompleks dilakukan pengolahan data hingga didapatkan penampang PSTM.

\section{Traveltime Tomografi}

Traveltime tomografi merupakan cara untuk merekonstruksi model kecepatan bawah permukaan yang memanfaatkan gelombang refraksi pada pengukuran seismik refleksi. Proses dari traveltime tomography yaitu membuat model awal / parameter dari picking first break data sintetik, kemudian dilakukan forward modelling dengan raytracing menggunakan metode straightforward ${ }^{[1]}$. Metode straightforward dilakukan dengan membagi model bumi menjadi beberapa grid dengan masing - masing kecepatan konstan pada Gambar X.

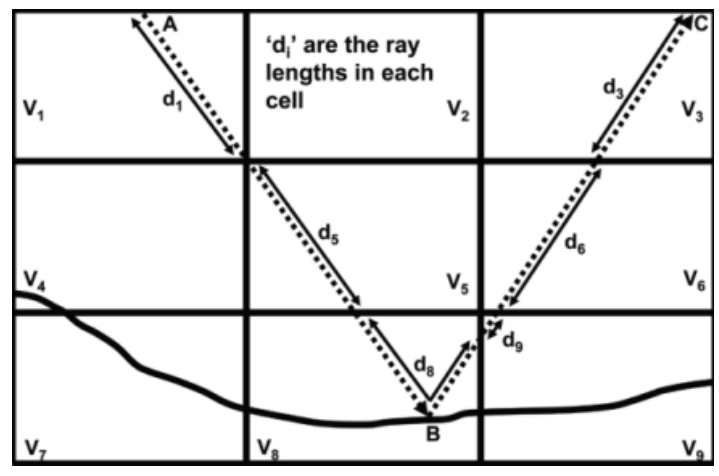

Gambar 3. Model bumi yang terdiri dari sel-sel kecepatan konstan, dengan total waktu tempuh adalah jumlah dari waktu tempuh tiap grid [2]

Waktu dari source A ke receiver $\mathrm{C}$ yaitu tABC, terdiri dari jumlah dari masingmasing segmen raypath dalam sel yang digambarkan sebagai berikut:

$t_{A B C}=\frac{d_{1}}{v_{1}}+\frac{d_{5}}{v_{5}}+\frac{d_{8}}{v_{8}}+\frac{d_{9}}{v_{9}}+\frac{d_{6}}{v_{6}}+\frac{d_{3}}{v_{3}}(1)$

dimana dj merupakan panjang raypath pada grid ke-j dengan kecepatan interval $\mathrm{v}_{\mathrm{j}}$. Pada proses tomografi traveltime forward modelling atau pemodelan kedepan cukup 
memakan waktu karena proses pergerakan gelombang (raytracing).

Proses tersebut dilanjutkan menggunakan inversi traveltime yaitu metode Gauss - newton (GN) untuk linearisasi fungsi objektif, setelah itu digunakan metode conjugates gradient (CG) untuk menyelesaikan inversi di setiap iterasi [3].

\section{Full Waveform Inversion Tomografi}

FWI atau inversi gelombang penuh merupakan suatu metode tomografi dengan merekonstruksi parameter bahan bawah permukaan (misalnya gelombang kompresi, gelombang geser, dan atenuasi) dari permukaan bidang gelombang elastis yang telah terjadi karena sumber atau gempa bumi $^{[4]}$. Persamaan gelombang yang digunakan FWI mengupdate parameter akustik terutama variable kecepatan gelombang (Persamaan 2) [5]. Dimana kecepatan yang didapatkan dari hasil traveltime tomografi sebelumnya digunakan sebagai input pada Persamaan 2. Kemudian dengan parameter densitas dan variabel $\mathrm{P}$ yang dianggap sebagai kecepatan diterapkan persamaan parsial differensial finite difference atau persamaan 1 dengan ordo 2 yaitu terhadap sumbu $\mathrm{x}$ dan $\mathrm{z}$ atau kedalaman karena berupa 2 dimensi. Sistem persamaan orde kedua dapat ditata sebagai kecepatan orde pertama hiperbolik stress dengan memasukkan variabel bantu yang diperlukan [4].

$$
\begin{aligned}
& \frac{1}{v^{2}} \frac{1}{\rho} \frac{\partial^{2}}{\partial t^{2}}=\mid \frac{\partial}{\partial x}\left(\frac{1}{\rho} \frac{\partial P}{\partial x}\right)+\frac{\partial}{\partial x}\left(\frac{1}{\rho} \frac{\partial P}{\partial y}\right)+ \\
& \frac{\partial}{\partial x}\left(\frac{1}{\rho} \frac{\partial P}{\partial z}\right) \mid
\end{aligned}
$$

Dimana FWI dapat dilihat sebagai teknik pemodelan iteratif maju karena pada setiap tahap iterasi model bumi diperbarui dan model yang diperbarui digunakan dalam iterasi berikutnya. Persamaan tersebut akan mengupdate $\mathrm{V}(\mathrm{x}, \mathrm{y}, \mathrm{z})$ secara iteratif dengan meminimalkan fungsi misfit pada Persamaan 3. Sehingga didapatkan kecepatan $\mathrm{V}$ yang telah di update dengan grid yang tetap. Dengan kata lain selisih kecepatan hasil Persamaan 2 FWI dengan kecepatan traveltime tomografi adalah iterasi pertama. Iterasi ini akan terus dilanjutkan menggunakan kecepatan iterasi sebelumnya hingga nilai $\mathrm{E}$ atau data obsevasi cukup kecil.

Semakin kecil nilai E, menunjukan bahwa data sintetik FWI memiliki kemiripan yang semakin tinggi terhadap data yang terekam di lapangan.

$$
\begin{aligned}
& E=\frac{1}{2} \Sigma_{s} \Sigma_{r} \int d t\left[P_{c a l}\left(x_{r}, t\right)-\right. \\
& \left.P_{o b s}\left(x_{r}, t\right)\right]^{2}
\end{aligned}
$$

\section{HASIL DAN PEMBAHASAN}

Dari dua buah model sintetik kecepatan traveltime tomografi $600-4000$ $\mathrm{m} / \mathrm{s}$ diwakili skala warna dari biru hingga merah muda. Hasil model sintetik sederhana menggunakan traveltime dengan 20 iterasi belum menunjukan anomali berkecepatan rendah, hanya anomali tinggi yang terlihat ditandai dengan objek kotak merah (Gambar 4.a). Sedangkan dengan FWI 5 iterasi sudah mulai menunjukan keberadaan anomali rendah pada kotak biru (Gambar 4.b).

Walaupun model kecepatan FWI tomografi belum menunjukan secara jelas letak objek anomali kecepatan rendah (ditunjukan pada kotak biru pada Gambar 4), tetapi objek tersebut sudah mulai menunjukan perbedaan kecepatan dengan lapisan di sekitarnya, sedangkan traveltime tomografi belum. 


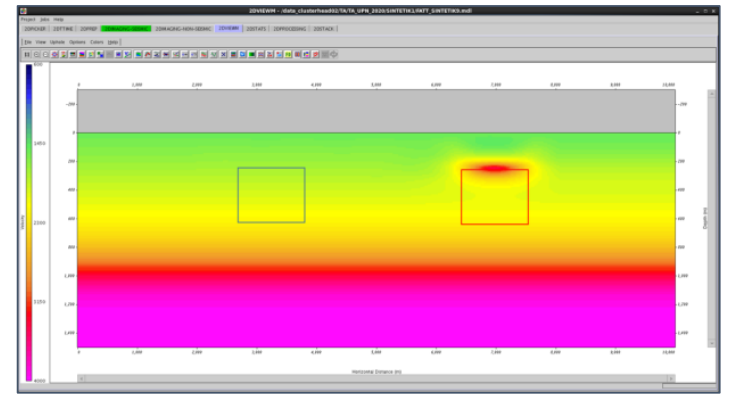

(a)

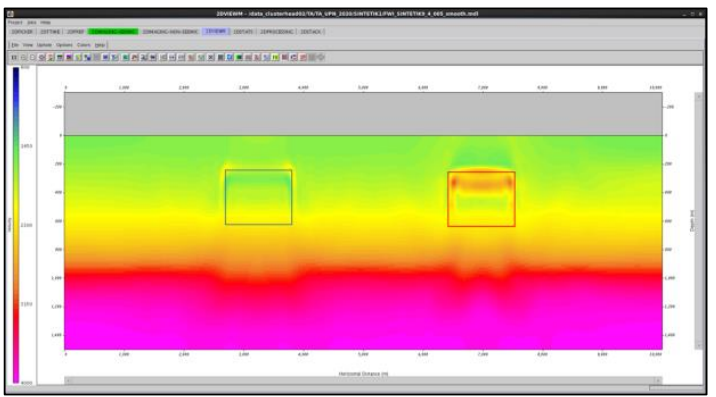

(b)

Gambar 4. Perbandingan model kecepatan sintetik sederhana dengan traveltime tomografi (a) dan FWI tomografi (b)

Kemudian dilakukan pengujian keabsahan dengan pemodelan tomografi model sintetik kompleks (Gambar 5) yaitu model kecepatan traveltime dan FWI dengan range $1200-3200 \mathrm{~m} / \mathrm{s}$ diwakili dengan skala warna biru hingga merah muda. Pada hasil 20 iterasi traveltime terlihat belum menunjukan lapisan anomali lapisan kecepatan rendah dengan baik yaitu pada kotak berwarna biru (Gambar 5.a). Tetapi setelah dilakukan FWI menggunakan 10 iterasi sudah mulai menunjukan keterdapatan lapisan anomali kecepatan rendah, terlihat lapisan tipis yang mewakili batas lapisan atas berwarna hijau serta menunjukan adanya struktur sesar dengan kontras kecepatan interval (Gambar 5.b).

Hasil ini sesuai dengan hasil pada pemodelan tomografi model sintetik sederhana sebelumnya. Dimana karena metode traveltime tomografi straight forward masih belum dapat menunjukan merespon adanya perbedaan kecepatan sedangkan metode FWI menggunakan model kecepatan traveltime dan SEG - Y sintetik sebagai inputnya dan mensolusikan persamaan dengan parsial differensial finite difference yang mengupdate parameter kecepatan secara iteratif.

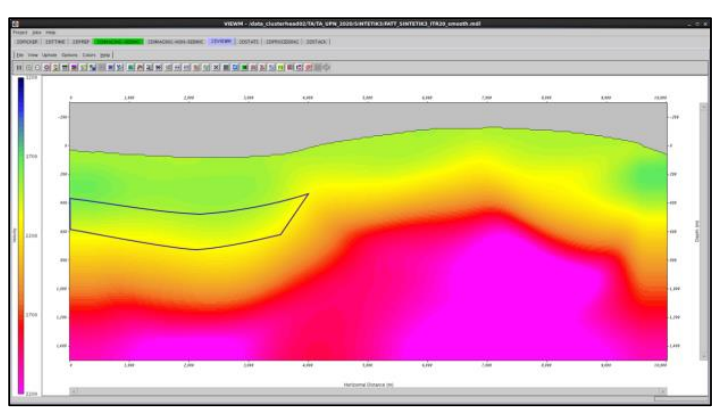

(a)

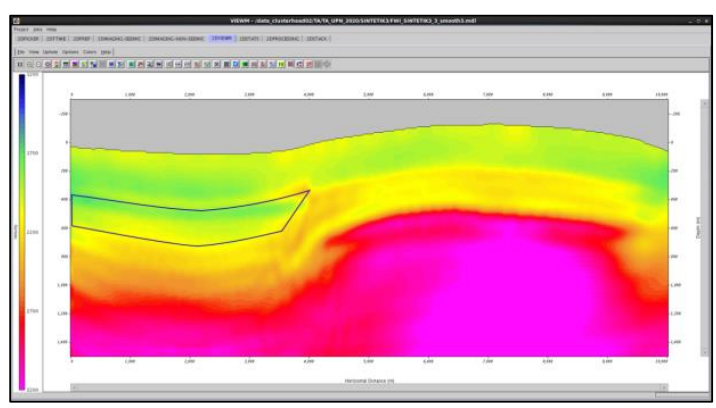

(b)

Gambar 5. Perbandingan model kecepatan sintetik kompleks dengan traveltime tomografi (a) dan FWI tomografi (b)

Quality control juga dilakukan pada hasil model kecepatan FWI sintetik kompleks, dengan melakukan overlay antara SEG - Y waveform synthetics dari forward modelling waveform synthetics, (hitam) dengan SEG - Y FWI (Merah). Hasilnya semakin banyak iterasi, kecocokan antara SEG - Y waveform synthetics dengan SEG - Y FWI semakin sesuai (Gambar 6) serta didukung dengan nilai error normal total misfit 38.928574 yang berarti memiliki kemiripan yang tinggi terhadap data yang terekam di lapangan. Model kecepatan FWI memiliki grafik waveform misfit of all shot yang menurun, dengan nilai error yang kecil, overlay yang sesuai, serta berhasil menunjukan adanya hidden layer low velocity \& struktur. 
Muhammad Akbar Najib .H: Tomografi Seismik Menggunakan Full Waveform Inversion Pada Studi Kasus Zona Kecepatan Rendah

Jurnal Migasian, e-issn : 2615-6695 / p-issn: 2580-5258

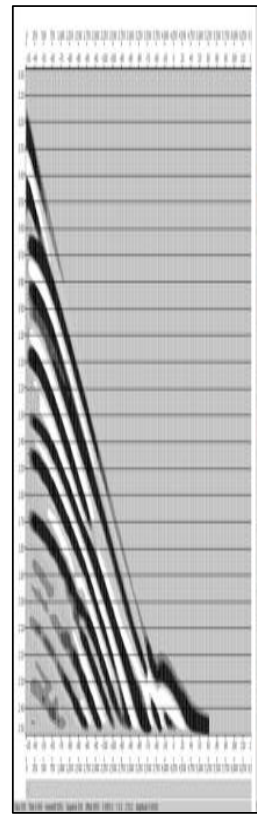

(a)

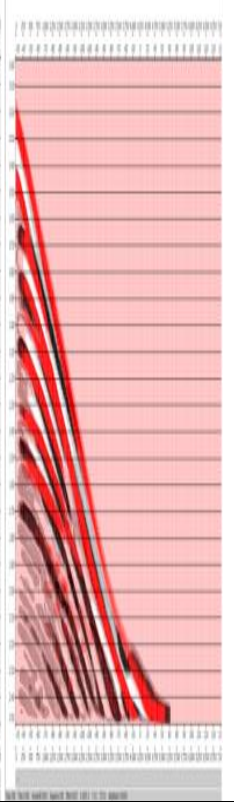

(b)

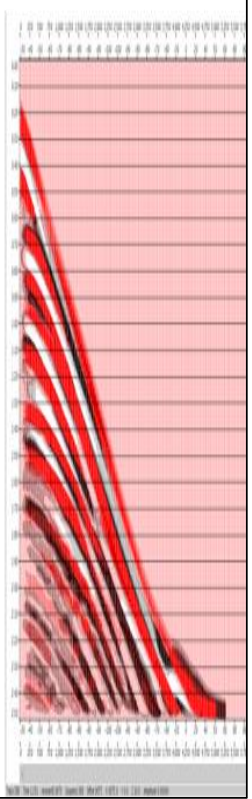

(c)

Gambar 6. Overlay waveform antara SEG - Y waveform synthetics (hitam) dengan SEG - Y hasil FWI (merah) pada shot ID 1. Sebelum dilakukan FWI (a), setelah 5 iterasi (b), setelah 10 iterasi (c)

Pada Gambar 7.a dan Gambar 7.b diperlihatkan dua seismik section yaitu PSTM yang menggunakan model kecepatan traveltime dan PSTM yang menggunakan model kecepatan FWI. Dapat dilihat seismik section hasil dari FWI terlihat lebih baik dibandingkan dengan hasil dari traveltime. Pada PSTM traveltime terdapat reflector yang kurang tepat sehingga tidak menunjukan batas lapisan anomali berkecepatan rendah, sedangkan FWI menunjukan dengan jelas batas lapisannya (ditunjukan dengan kotak biru). Kemudian dalam penggambaran struktur sesar, FWI menggambarkannya dengan lebih jelas dimana traveltime lebih menunjukan kemenerusan lapisan dibanding terpotong oleh struktur dalam domain waktu (ditunjukan dengan kotak merah). Hal ini dikarenakan PSTM FWI yang menggunakan hasil koreksi statik dengan model kecepatan FWI tomografi, sehingga resolusi hasil PSTM menjadi lebih maksimal.

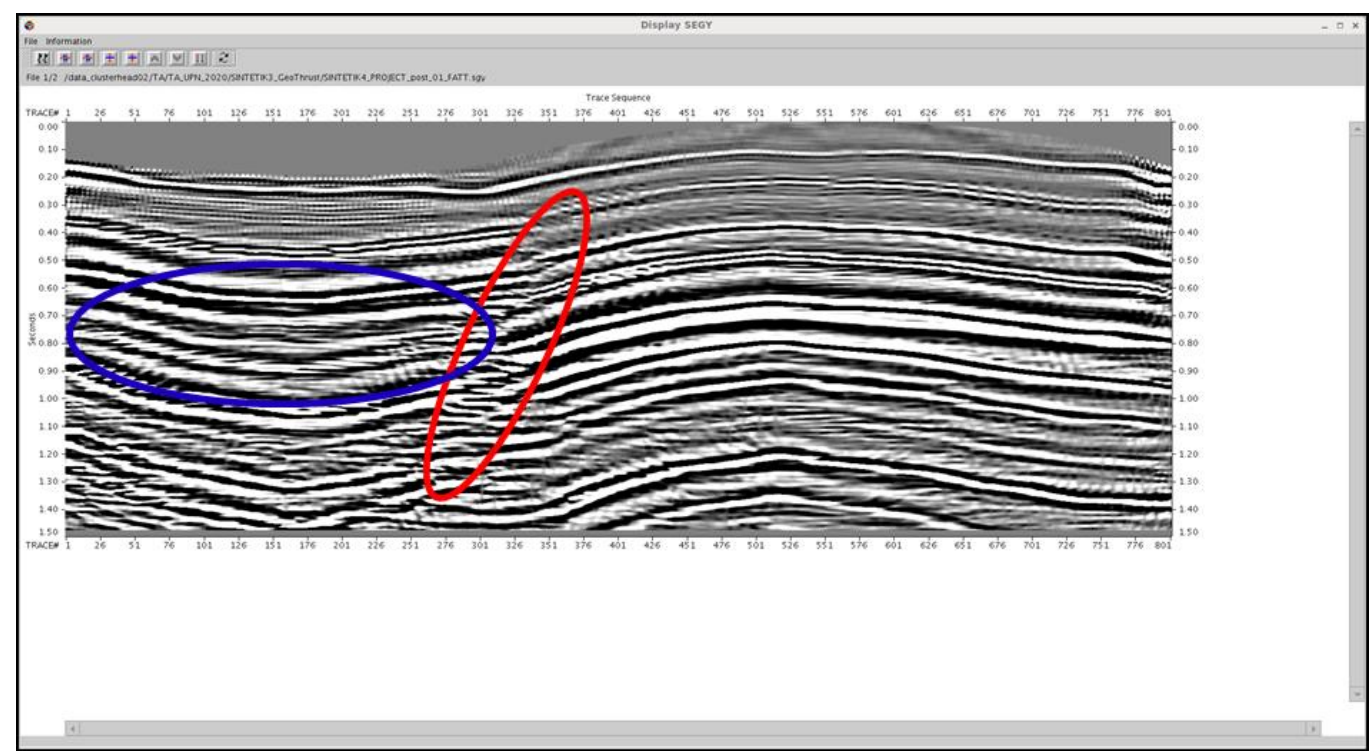

(a) 


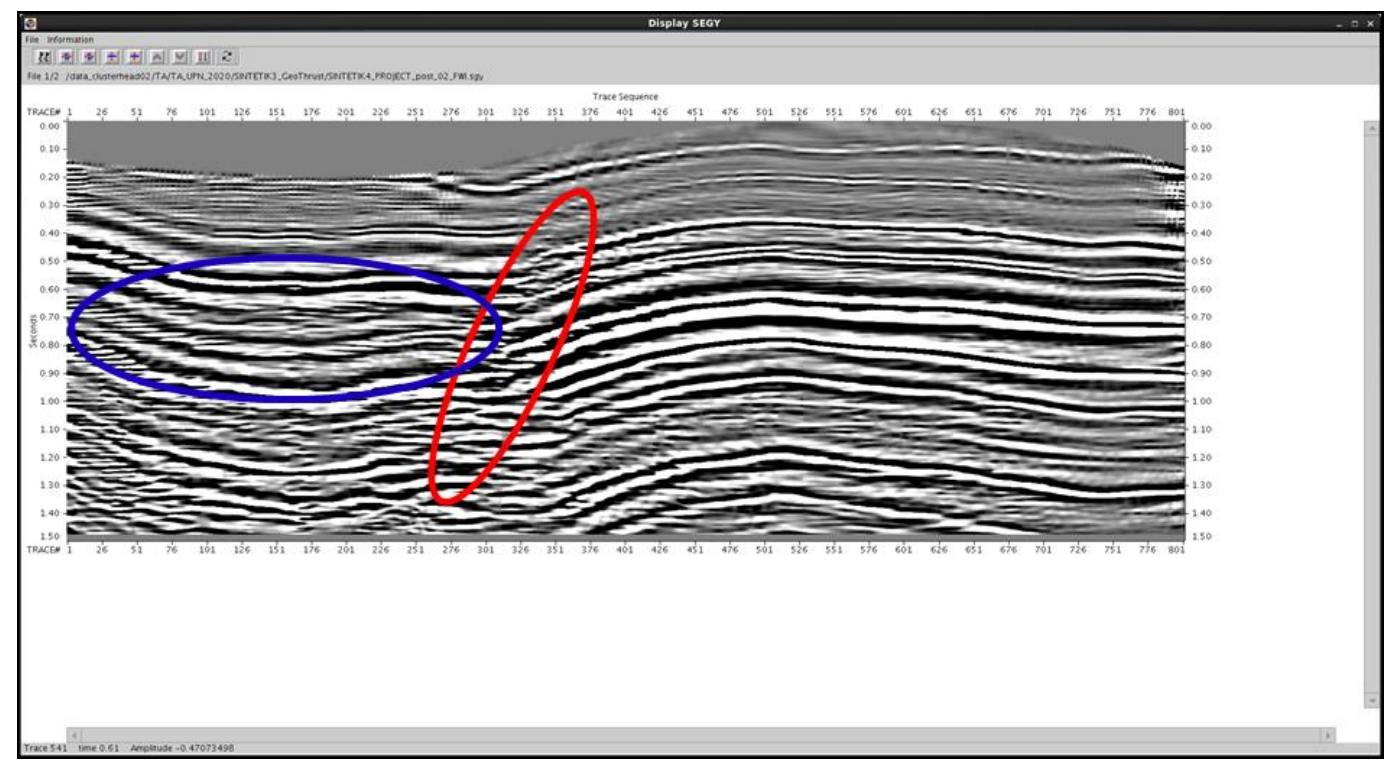

(b)

Gambar 7. Perbandingan hasil penampang dengan static hasil travel time tomografi (a) dan FWI tomografi (b)

\section{KESIMPULAN}

Model kecepatan FWI dapat menggambarkan batas lapisan hidden layer low velocity lebih baik daripada model kecepatan traveltime. Hal ini dikarenakan perhitungan FWI menggunakan metode finite-difference dalam memperbaruhi model yang diiterasikan. Dengan menggunakan model kecepatan FWI sebagai input pengolahan data dan koreksi statik, meningkatkan penggambaran PSTM section pada batas lapisan hidden layer kecepatan rendah, struktur sesar, dan kontinuitas dibandingkan penampang PSTM yang menggunakan model kecepatan traveltime.

Untuk penelitian kedepannya bisa mempertimbangkan penggunaan data seismik real dan metode migrasi Pre Stack Depth Migration (PSDM) dengan model kecepatan FWI untuk meningkatkan resolusi vertikal dan horizontal dalam domain kedalaman.

\section{UCAPAN TERIMAKASIH}

Kami mengucapkan terimakasih kepada PT. Jaya Energy Buana dan GeoTomo LLC, yang telah mengizinkan kami menggunakan software TomoPlus dan GeoThrust untuk melakukan studi ini serta izin untuk menerbitkan paper ini.

\section{DAFTAR PUSTAKA}

[1] Anshori , M., Maryanto, S., \& Rahman, T. D. "Pencitraan Tomografi ambient Noise untuk Menentukan Model Kecepatan Gelombang Rayleigh Di Pulau Jawa". ITB, Bandung, 2014.

[2] Jones, I. F. "Velocity Estimation Via Ray-Based Tomography”. ION GX Technology, UK, 2010.

[3] J. Zhang, "Nonlinier Refraction Traveltime Tomography", Geophysics, vol. 63, pp. 1726 - 1737, 1998. 
Muhammad Akbar Najib .H: Tomografi Seismik Menggunakan Full Waveform Inversion Pada Studi Kasus Zona Kecepatan Rendah

Jurnal Migasian, e-issn : 2615-6695 / p-issn: 2580-5258

[4] A. Tarantola, "Inversion of seismic reflection data in the acoustic approximation", Geophysics, vol. 49, pp. 1259-1256, 1984.
[5] J. Virieux, "P - SV wave progradation in heterogeneous media velocity stress finite difference method", Geophysics, vol. 51, pp. 899-901, 1986. 